\title{
Cenários urbanos contemporâneos: novas ou velhas práticas no Brasil e na Amazônia? ${ }^{1}$
}

\section{Neli Aparecida de Mello-Théry ${ }^{1}$ e Hervé Théry ${ }^{2}$}

1 Escola de Artes, Ciências e Humanidades, Programas de pós-graduação em Geografia e Ciência Ambiental, USP, Brasil. Email: namello@usp.br;

2 Programa de Pós-Graduação em Geografia Humana. Depto. de Geografia, USP, Brasil. E-mail: hthery@aol.com.

RESUMO: O presente artigo analisa algumas características dos problemas urbanos brasileiros, com foco na Amazônia, utilizando informações estatísticas disponíveis em instituições governamentais e considera, especialmente, alguns indicadores relacionados à capacidade operativa dos governos locais: De um modo geral, estes indicadores refletem parcialmente as disparidades existentes no país. Contextualiza, portanto, a questão urbana nas ultimas décadas, destacando suas direções e tendências. O mapeamento de variáveis selecionadas serviu tanto como analise da base de vetores de política publica e de sua capacidade de execução, bem como se pode concluir acerca das consequências sobre a organização do espaço e ações publicas que surgem destas dinâmicas.

Palavras-chave: dinâmicas urbanas, avaliação dos territórios, planejamento, política pública

Contemporary urban settings: new or old practices in Brazil and in the Amazon? ABSTRACT: The paper analyses some specific characteristics of the Brazilian and Amazonian urban problems, making use of available statistical information and considering indicators of operating capacity of local governments. These indicators reflect some of the disparities in Brazil and contextualize the urban question in recent decades, highlighting directions and trends. Mapping some variables helps to describe public policy vectors, the consequences on the organization of space and public actions arising from these dynamics.

Keywords: urban dynamics, evaluation of territories, planning, public policy

As dinâmicas urbano-metropolitanas brasileiras são marcadas por inovações tecnológicas e por serem nós de redes técnicas, pelas quais se inserem nos circuitos globais de produção e se articulam com o mundo. Além de reestruturarem o espaço concentram mais da metade do PIB do país. Assim, ao identificá-las e mapeá-las objetiva-se compreender os cenários brasileiros, com foco na Amazônia, nas primeiras décadas do século XXI.

Para a compreensão das práticas políticas no cenário brasileiro, o processo de urbanização, pautado na ilusão de uma disponibilidade de espaço quase infinita, remodelou profundamente as paisagens urbanas e rurais e transformou a sociedade. $\mathrm{Na}$ segunda metade do século $X X$, a urbanização foi uma das vertentes da modernização brasileira e estimulou a mobilidade social e espacial por meio do avanço da frente

\footnotetext{
${ }^{1}$ Este artigo, com abordagem mais geral, foi originalmente apresentado no XII Coloquio de Geografia Urbana Colourbana 2016, realizado em Girona, Espanha, tendo sido modificado parcialmente para este dossiê.
} 
pioneira, ao incorporar novas fronteiras, formar novas cidades e municípios, o que, simultaneamente, produziu e agravou as desigualdades e as disparidades socioespaciais. As configurações atuais refletem-nas, seja pelos sistemas de cidades bem hierarquizados em algumas regiões ou ainda em construção, sobretudo no norte do país.

Os cenários desse início de século XXI apontam para dois fortes vetores: a metropolização e a inovação. Colocados em perspectivas com as ações políticas mais recentes de sustentabilidade urbana (Habitat II, 1997; MMA/PNUD, 1999; Estatuto da Cidade, 2001) são adotados como marcos de referência institucionais, entendendo, como Brandão (2004), que atualmente os temas urbanos são vistos pelas lentes da competitividade, do marketing, do planejamento estratégico (Fonseca e Ramos, 2004). Os problemas podem ocorrer em múltiplas escalas (Smith, 2000, p. 144), pois ela "demarca o sitio da disputa social, tanto o objeto quanto a resolução dessa disputa". Exige, portanto, compreender que, em algum momento, um problema real poderá ocorrer em uma escala, mas ter sua resolubilidade em outra. Pode não estar nas mãos do poder local, como, por exemplo, as ações publicas decorrentes do Programa Minha Casa, Minha Vida, do governo federal, mas, cujos reflexos, por vezes de (in)sustentabilidade, sucedem localmente.

A metropolização brasileira e amazônica, ao invés de promover maior equilíbrio, impeliu e reproduziu as fortes disparidades territoriais e desigualdades sociais. A modernização não se fez com superação visto que, muitas das políticas implantadas do final do século XX para a atualidade, para serem universais, tratava de maneira semeIhante, territórios, territorialidades e sociedade diversificados. Encontra-se neste aspecto, o maior dilema das políticas e ações publicas: universalizar ou particularizar.

Metodologicamente a construção de nosso raciocínio fundamenta-se na utilização de informações estatísticas e censitárias, tendo como fontes os dados gerados pelo IBGE no estudo Regic (Regiões de influência das cidades) e no Perfil dos Municípios Brasileiros. Tais informações estatísticas servirão de indicadores para este artigo. Selecionaram-se algumas dentre as 241 variáveis elaboradas a partir da coleta de informações, que permitam representar na forma de mapas ${ }^{2}$ as áreas de influência das metrópoles, a infraestrutura, a mobilidade urbana e os equipamentos culturais, sempre destacando a Amazônia legal por meio de uma linha de cor contrastante. Este conjunto de dados (associado à análise das políticas e instrumentos de gestão, aos gastos municipais com habitação e urbanismo e à condição de funcionários municipais para a sua execução) permitirá analisar se os governos municipais as observam na elaboração de suas políticas e quais são os instrumentos de gestão territorial que esses municípios dispõem.

\footnotetext{
${ }^{2}$ Realizados (pelo menos na sua fase inicial) em softwares de tratamento estatístico e de cartografia gratuitos ou de baixo custo para estudantes e professores, Philcarto (http://philcarto.free.fr/) e Cartes et Données (http://www.articque.com/geocampus/).
} 


\section{A QUESTÃO URBANA NO SÉCULO XXI}

A integração das regiões mais periféricas foi efetuada principalmente pela ação dos poderes públicos e em função dos interesses do centro-sul. E o caso explícito da Amazônia, vista como uma reserva de recursos naturais e um mercado a conquistar. As ações decorrentes dessas políticas serviram de alicerce à implantação e à consolidação de setores produtivos urbanos, a partir dos quais a modernização rural era empreendida. $O$ desenvolvimento e a consolidação de cidades médias coincidiram com a gradativa redução das migrações que alimentavam o crescimento das metrópoles brasileiras. Porém, tanto as migrações a curta distância, como as migrações remotas que as precediam, apresentaram a mesma consequência: o agravamento das desigualdades sociais nas cidades e a exclusão de uma parcela significativa dessa população dos benefícios da vida urbana. Nesse contexto de forte crescimento das grandes cidades, verdadeiras aglomerações urbanas criaram-se progressivamente, articulando espaços tradicionais com espaços de modernização. Cidades médias, no Sudeste e no Sul, transpuseram seus limites municipais, conurbando e formando aglomerações, entre si e, às vezes, com as grandes capitais. Becker e Stenner (2009) distinguem para a Amazônia três categorias de cidades: i) as da floresta, estrategicamente localizadas que podem organizar a estrutura produtiva da região, ii) as conectadas às redes e cidades e iii) a cidade urbanizada na floresta, que deve gerar inovações.

Para eles, Manaus é uma cidade mundial no meio da floresta por sua posição privilegiada em momentos históricos distintos, mas também criticada por ser um enclave regional, reinando sobre quase todo o território do Estado e por concentrar benefícios em apenas algumas partes da cidade, contribuindo para agravar a pobreza, o desemprego, a violência, a desigualdade. Além disso, a cidade deve se antecipar, assumindo riscos e se planejando, buscando agregar valor com os serviços ambientais prestados, aproveitando-se da posição estratégica e geográfica que ocupa na bacia amazônica. Belém, com mais de 400 anos, de cidade da borracha transformou-se em cosmopolita, moderna e exerce influencia como metrópole regional. Seu processo de verticalização iniciou-se na década de 1940, tendo intensificado nas duas ultimas décadas. Nessa cidade cosmopolita, cada vez mais, os megaempreendimentos comerciais (shoppings centers) e residenciais (condomínios fechados) isolam e alteraram a interação entre habitantes e reforçam a segregação social e territorial e, sobretudo, abrem-se ao mundo da violência.

\subsection{Atrações, direcionamentos e tendências}

Diversos fatores contribuem para a dinâmica espacial, dentre os quais as hierarquias e a capacidade de uma cidade em atender necessidades não satisfeitas localmente, construindo, assim redes e sistemas urbanos. Insere-se, neste contexto, a cri- 
ação de Regiões Integradas de Desenvolvimento (RIDE) e de novas regiões metropolitanas, ampliando o seu número de 9 para 23 fundamentada pelo estudo do governo federal (IPEA, 2001; IBGE, 2000, DTB-IBGE, 2006) o que, certamente, readequa as redes e os sistemas. São somente duas regiões metropolitanas na Amazônia, a de Manaus (criada em 2007) e Belém (criada em 1973, alterada em 1995, 2010 e 2011). Como os Estados têm autonomia para também constituir regiões metropolitanas ou aglomerações, passaram a integrar o conjunto, Macapá, o Sudoeste Maranhense e o Vale do Rio Cuiabá.

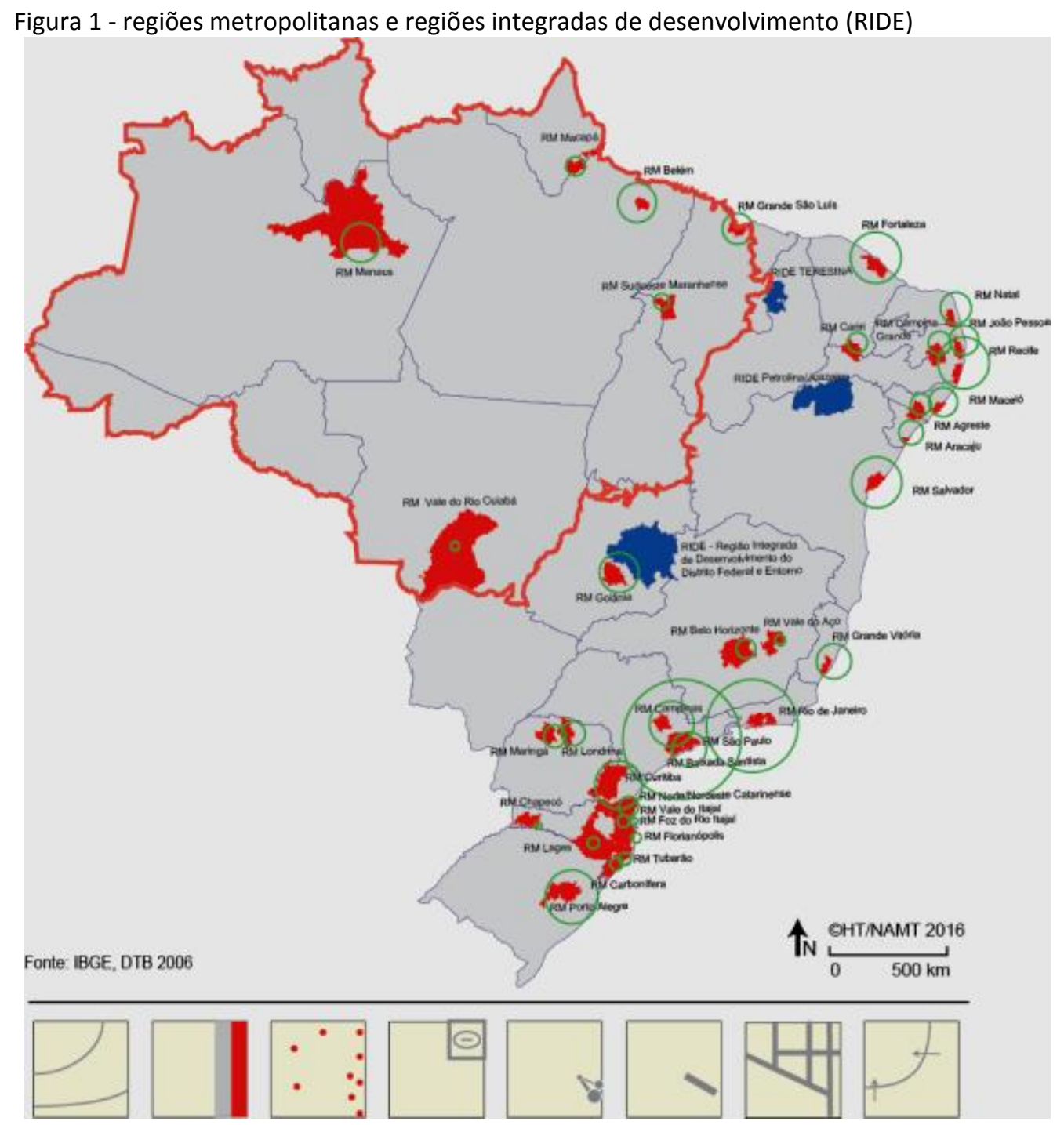

Os sistemas tradicionais das atrações urbanas são impulsionados para aceitar as evoluções constantes, como a formação de novas vilas e povoados e a sua transformação em sede de novos municípios. Acoplados com o desenvolvimento da infraestrutura e com a melhoria dos serviços, esses novos locus do poder municipal reestruturam suas áreas de influência, reorganizam suas redes de relações, tornam-se polos 
mais competitivos e aumentam sua capacidade de polarização. Comecemos a análise pelas áreas de influência das metrópoles:

\subsubsection{As áreas de influência das metrópoles}

A caracterização destas áreas passa pela análise da localização dos diferentes nós (os polos principais) com seus níveis de relacionamento e hierarquia. Identificou-se, na atualidade. Essa análise permite conhecer o grau de maturidade e descentralização ou centralização do poder territorial, esse último centrado em algumas grandes metrópoles nacionais, o que é agravado pela ausência de cidades médias atrativas, no contexto brasileiro. Fundamentada sobre uma bateria de indicadores (comando administrativo, área de atração dos serviços educativos e saúde, área de atração comercial etc.), as pesquisas do IBGE (2000) com base em dados de 1993, permitiram classificar as cidades em oito hierarquias de atração (máxima, muito forte, forte, forte à média, média, média à fraca, fraca) expandindo para 11 níveis em 2007 (grande metrópole nacional, metrópole nacional, metrópole, capital regional $(A, B$ e $C)$, centro de zona (A e B) e centro local (IPEA, 2001; IBGE, 2000)).

O fato mais visível é a dimensão da área de atração de São Paulo (a grande metrópole nacional) que engloba grande parte do Centro-Oeste e da Amazônia. Nenhuma outra cidade consegue rivalizar com essa metrópole que se tornou a verdadeira capital econômica do País. As outras cidades dessa categoria são, sem surpresa, os municípios centrais das outras regiões metropolitanas de primeira hierarquia, à exceção de Belém, a menor entre elas (apenas dois municípios), e com o acréscimo de Goiânia, que irradia amplamente sobre o restante do Centro-Oeste e sobre algumas porções da Amazônia (sul do Pará) e do Nordeste (Maranhão). Geralmente, Goiânia drena toda a extensão do atual Estado de Tocantins, que anteriormente estava sob sua influência, e Brasília que, decididamente, assume muito mais o papel de capital federal que de metrópole regional.

Pelo estudo, o alcance da influência da metrópole do Rio de Janeiro também reduziu muito, até mesmo em suas fronteiras, onde São Paulo exerce atração. Essa se adentra nos interstícios onde a atração das outras metrópoles é mais fraca, no Sul e no Nordeste (sul da Bahia, Alagoas, Piauí e Maranhão). No Norte, Manaus e Belém compartilham sua influência em nível mais local porque praticamente toda a bacia amazônica está sob a influência de São Paulo, com uma superposição no leste do Pará, uma região bem distante de Belém, onde o rio Amazonas permite uma comunicação mais fácil com Manaus. No Nordeste, a área de atração de Fortaleza reduziu-se ao próprio Estado, e Salvador concorre com Recife, além da de Feira de Santana (que abre um "buraco" bem visível na sua área de atração). A área de Recife ultrapassa os limites de Pernambuco ao longo do rio São Francisco, onde se desenvolveu a fruticultura irrigada. Situada entre as influências de Belo Horizonte e Goiânia, Brasília tem dificuldade de encontrar o seu espaço próprio, disputando a conquista de regiões 
como o Nortão do Mato Grosso, pelas relações diretas com o governo federal e o oeste da Bahia, talvez por falta de concorrência, visto que o Além São Francisco, recentemente conquistado pela cultura da soja, era até então pouco polarizado.

Entre os centros de segunda hierarquia, devem-se distinguir situações bem diferenciadas. Algumas cidades irradiam sua influência sobre vastos espaços, como Manaus e Belém, na Amazônia, ou São Luís do Maranhão, no Nordeste. Eram, há pouco tempo, capitais regionais de primeira classe, mas perderam autonomia, sendo captadas na órbita de São Paulo. Outros concorrem com cidades de nível superior, como Feira de Santana com Salvador, Caruaru com Recife, Juiz de Fora com Belo Horizonte. Por último, outros núcleos urbanos estão em concorrência entre si, em regiões onde são numerosos e próximos uns dos outros, como no Sul e, sobretudo, no Estado de São Paulo, onde as antigas cidades do café formam uma rede densa e consolidada. Em uma escala maior e descendo a hierarquia das áreas de atração, surgem, nos "brancos" desses dois mapas, outros centros menores, que oferecem serviços mais comuns e polarizam zonas menores. As figuras 2 e 3 espacializam estes fenômenos, representando as áreas de atração a partir de dados estatísticos do conjunto de indicadores analisados, enquanto a figura 3 representa, a partir de um modelo teórico (Huff), utilizando algoritmos derivados da lei da gravitação, tal qual a atração de um planeta que é função de sua massa e inversamente proporcional ao quadrado de sua distância. Neste contexto, Manaus e Belém concentram, obviamente, essa polaridade. As outras capitais da região amazônica "desaparecem" do cenário nacional. 
Figura 2 - áreas de atração das principais cidades

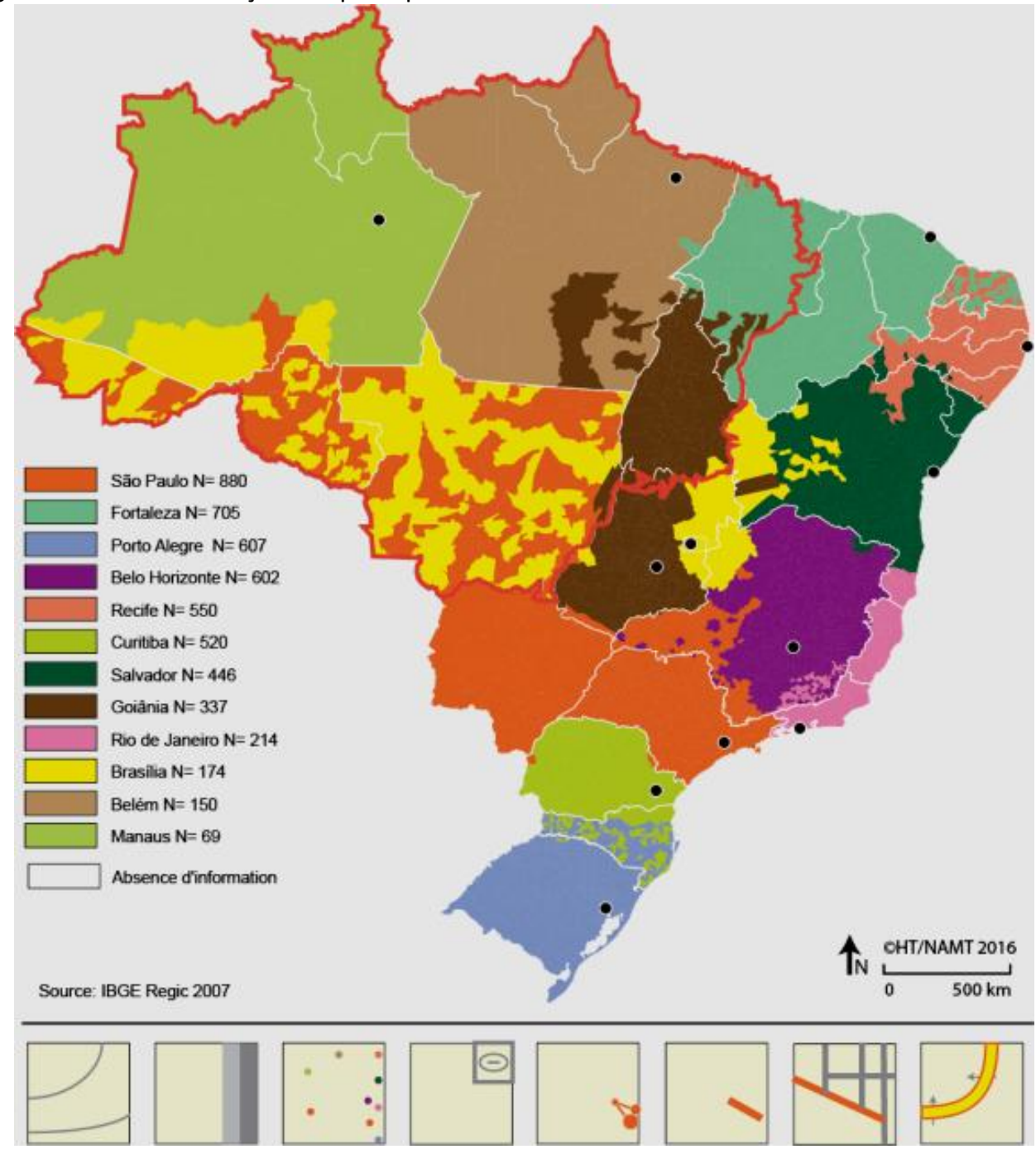


Figura 3 - Áreas de atração teórica dos centros urbanos, com base na população

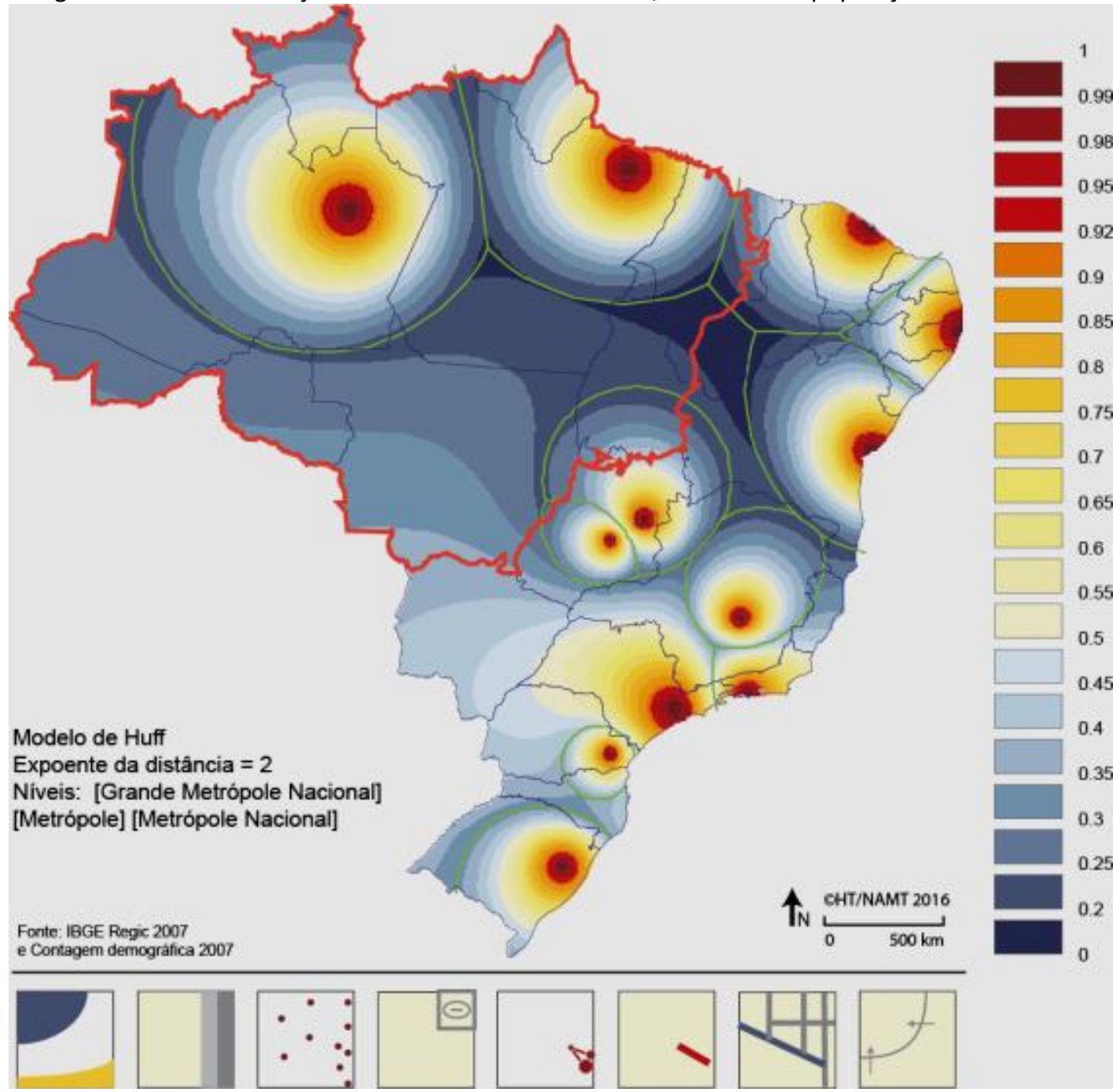

\subsubsection{A infraestrutura}

Fragmentação e coexistência são dois fenômenos presentes nas cidades brasileiras visto que bairros com infraestrutura impecável, reservados aos setores produtivos de tecnologia de ponta ou a residências de luxo se localizam à curta distância de bairros miseráveis, sem infraestrutura sanitária e marcados por problemas ambientais graves. A ausência, ou a insuficiência, dos investimentos públicos nos domínios da distribuição da água potável, do tratamento de águas residuais, da coleta de lixo nesses bairros pobres gera, por consequência, graves problemas de saúde pública aos seus habitantes. Nesses mesmos bairros também os serviços públicos de saúde, educação e segurança são deficientes. Em nenhum outro lugar a situação é tão grave como nas favelas do Rio de Janeiro, onde as autoridades públicas praticamente renunciaram a ação e cuja gestão abandonaram aos traficantes de drogas. Contudo, outras cidades brasileiras conhecem, igualmente, situações que chocam o sentido de justiça e que constituem imensos desafios - ou ameaças - para as autoridades políticas. 
A marginalização das populações e dos bairros pobres não se apresenta da mesma maneira em todas as cidades. Do ponto de vista das condições de habitabilidade, o IBGE, para os domicílios particulares permanentes, definiu três categorias (adequados, semi-adequados e inadequados) e identificam-se as condições inadequadas ou semi-adequadas como predominantes nestes bairros. Incluem-se no âmbito das condições do abastecimento de água (rede geral, poço ou nascente ou outra forma), do saneamento (rede geral de esgoto ou fossa séptica), do serviço de limpeza urbana (coleta de lixo, queima ou disposição em qualquer tipo de terreno) e a quantidade de moradores por dormitório (até 2 ou mais).

Figura 4 - Condições de habitabilidade

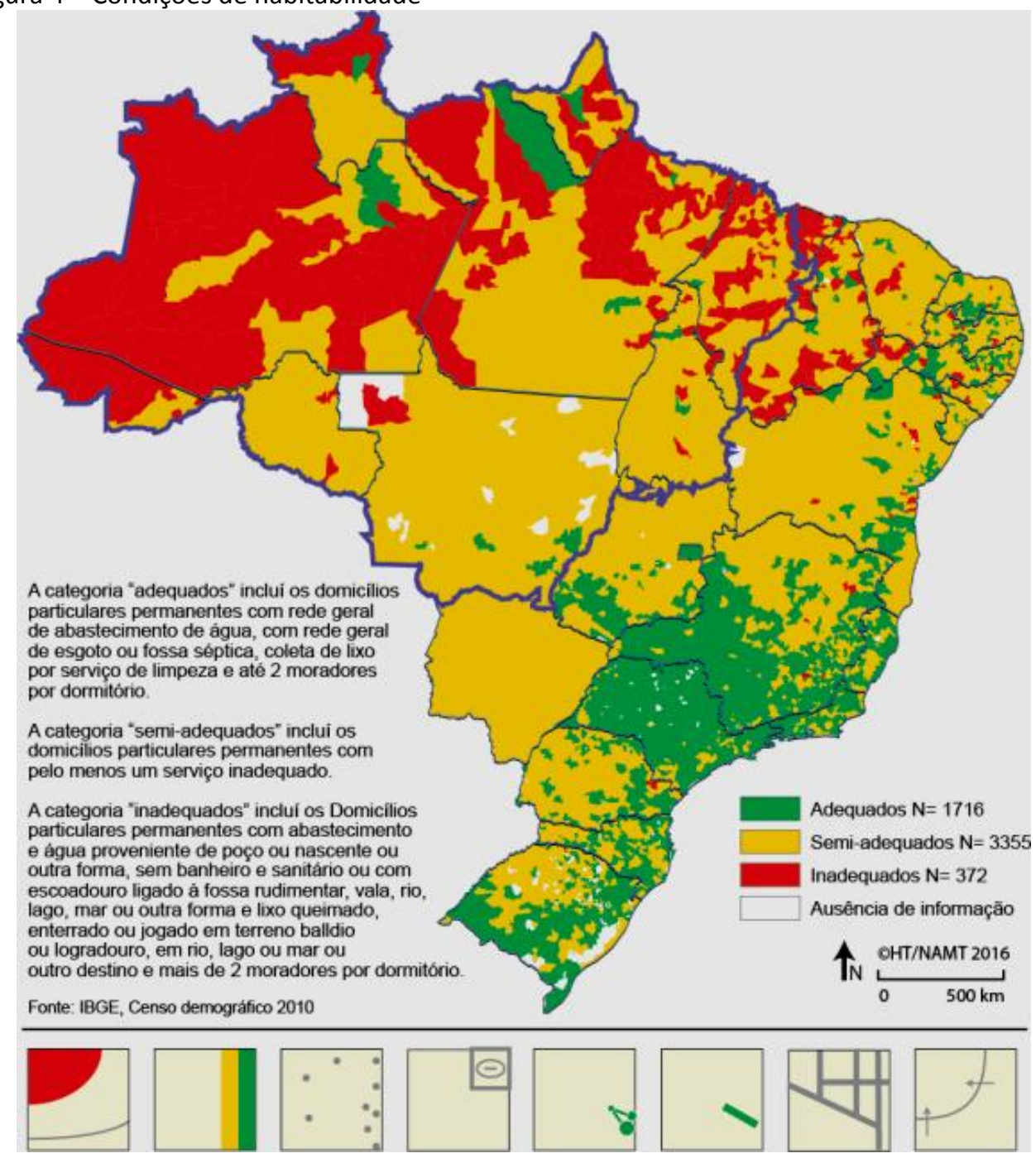

\subsubsection{A mobilidade urbana}

A mobilidade urbana expressa pelo tempo de deslocamento é outro aspecto a se considerar quanto à problemática urbana do século XXI. Tem sido um dos fatores de perda de qualidade de vida nas metrópoles e grandes cidades, em razão sobretudo, 
da dificuldade de completar os percursos casa-trabalho-casa e, eventualmente, lazer em pouco tempo. Nos transportes públicos um dos maiores gargalos é sua insuficiência e qualidade: são poucas as opções, predomina o transporte rodoviário sobre o ferroviário, as linhas de metrô são inexistentes ou insuficientes e as ciclovias somente começaram a ser implantadas recentemente. Ao lado disto, muitos incentivos para a compra de automóveis, prevalecendo o uso do transporte individual. Resultado, em todas as microrregiões metropolitanas e capitais brasileiras, o tempo de deslocamento é de mais de trinta minutos; nas microrregiões com cidades médias os percursos necessitam entre 6 e 30 minutos e somente nas microrregiões com predomínio de pequenas cidades é que o tempo de deslocamento não chega a 5 minutos.

Nas microrregiões das três principais capitais amazônicas ja prevalecem mais que 30 minutos para deslocamentos, enquanto em cidades medias destes estados, predomina o tempo de 6 a 30 minutos na ação de deslocar.

Figura 5 - Tempo e transporte e população

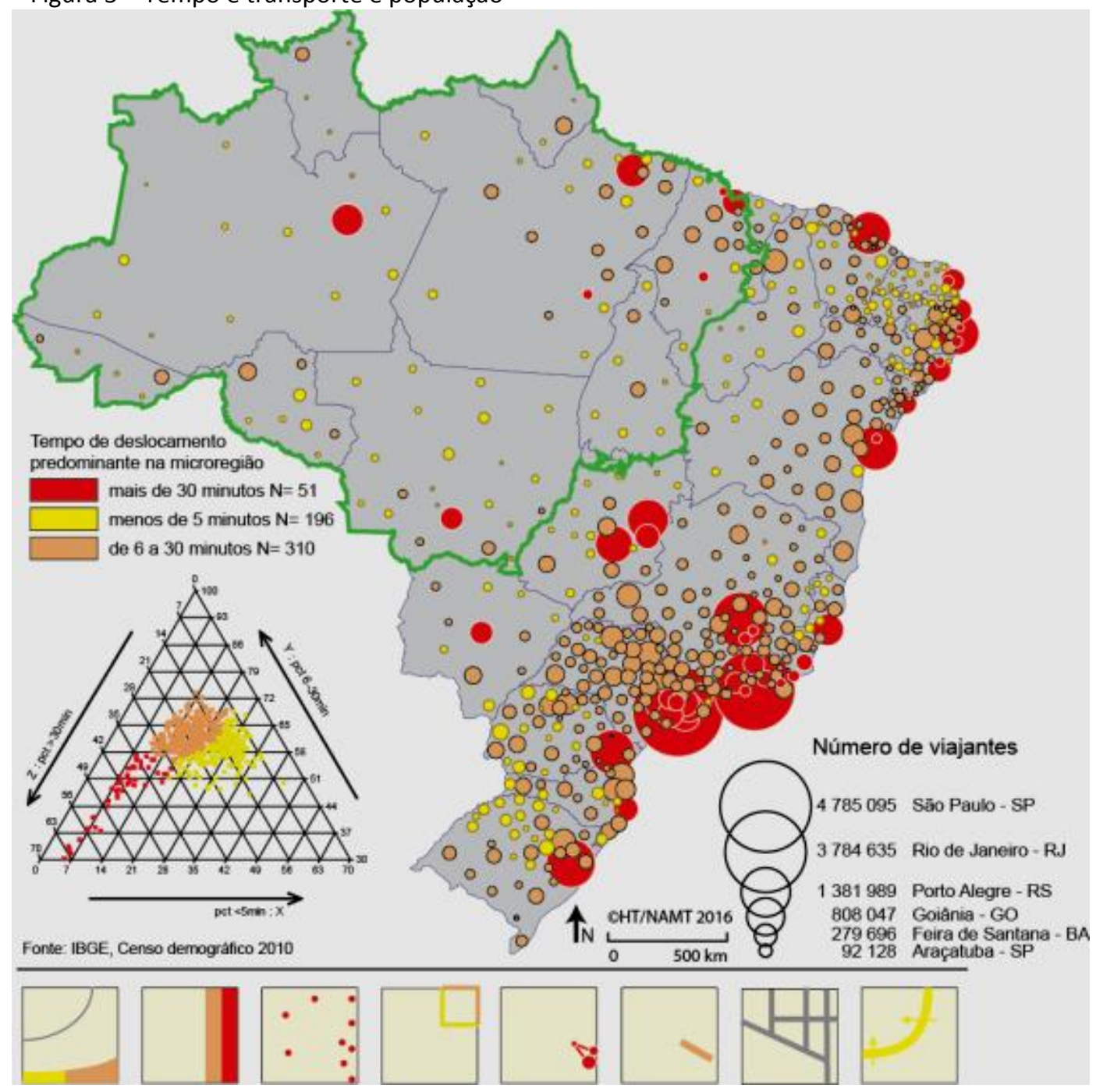

PRACS: Revista Eletrônica de Humanidades do Curso de Ciências Sociais da UNIFAP 


\subsubsection{Os equipamentos culturais}

O tema dos equipamentos culturais é outro que pode ser analisado a partir do mapeamento de variáveis censitárias. Consideramos equipamento cultural desde museu, teatro ou sala de espetáculo, arquivo público ou centro de documentação, cinema e até shoppings, vistos como locais de troca e de disseminação de cultura por ser, cada vez, mais a localização preferencial de cinemas. São equipamentos que contribuem para democratizar a cultura e integrar populações, mas no país a desigual distribuição reflete as desigualdades socioeconômicas. Assim, considerando-se sua presença por área $\left(\mathrm{km}^{2}\right)$ e estabelecendo uma relação, por meio da média com os municípios vizinhos, destacam-se dois grandes conjuntos de concentração: a) no eixo da macrometrópole paulistana e nos estados do sul do país; b) nas capitais do Nordeste e nas suas proximidades. Uma grande dispersão pelo interior ocorre no restante do país, com a presença extremamente baixa (variação entre 0,01 e 0,7 ) de equipamentos culturais.

No que diz respeito aos conceitos, analises a respeito de bens culturais e seu consumo pelas sociedades não ha nenhuma unanimidade, mas ha muitas convergências, na apreciação de que a educação é um fator importante do capital humano, pois contribui para a capacidade de processamento e assimilação de informações e que a apreciação de bens artístico-culturais depende do nível de educação do indivíduo.

A ausência de infraestrutura cultural demonstra a ausência de política pública voltada para esse importante segmento da vida urbana, sendo o caso de todos municípios amazônicos: somente as capitais conseguem ser classificadas na faixa de 0,7 a 1,7 e Belém que passa para a categoria imediatamente superior; entre 1,7 a 2,92. 
Figura 6 - Equipamentos culturais

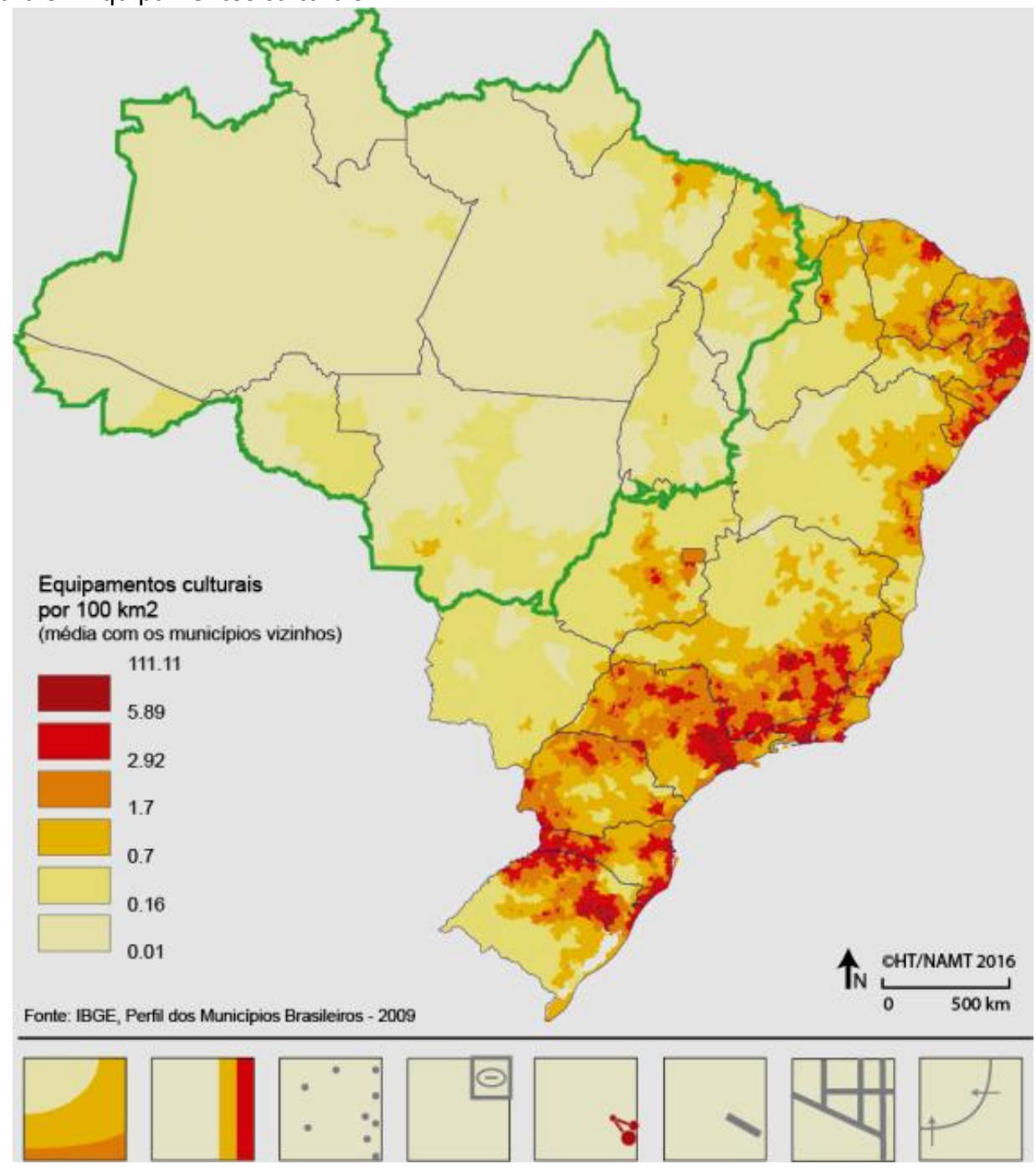

Considerando-se a variável distribuição dos equipamentos, é possível identificar espaços de modernização do território e a presença dos mesmos como elementos constituintes do modelo de desenvolvimento. Desta maneira, as políticas de incentivo culturais se inscrevem nas tendências decorrentes do processo de urbanização e de metropolização mundiais.

\section{AS POLÍTICAS PÚBLICAS MUNICIPAIS, PLANEJAMENTO E CAPACIDADE DE EXECU- ÇÃO}

Elaborar políticas públicas que sejam positivas à sociedade, à melhoria das condições de vida dos cidadãos e contribuam, de fato, para o desenvolvimento local é um enorme desafio. De um lado porque deve resultar de decisões políticas de longo prazo, de debates com segmentos distintos da sociedade, mas, também de visões e compromissos de longo prazo. 
Visões de longo prazo implicam, obviamente, em planejamento e em processo de decisões. No caso brasileiro, cada dia mais se perde esta noção de planejar, confundindo ações de governo com ações de Estado. Políticas passaram a ser ações de governos, contrapondo, desta maneira, à formação ou consolidação de uma cultura de planejamento de Estado. Enfocando o processo de planejamento, que depende de informações e sua analise, a partir das quais se procurem soluções em questões que possam afetar as sociedades, o funcionamento dos espaços urbanos e rurais e seu processo de desenvolvimento. Em política e planejamento, normalmente, a maior expectativa é que se cumpram as leis e regulamentos em vigor, estas oriundas de processos e decisões técnicas, embora possa se induzir que as orientações e propostas indicativas devam ser apoiadas na própria sociedade.

Schweizer (2008) considera que a existência destas componentes impositivas (leis e normas) à primeira vista pode demonstrar uma prática não democrática do planejamento, porém, questões indispensáveis à vida humana não podem ficar sujeitas aos interesses que possam prejudicar a toda uma coletividade, como por exemplo, a preservação dos mananciais que garantam, no futuro, o abastecimento de água a todos. O planejamento democrático, está ligado ao processo de tomada de decisões de todos aqueles que se encontram em posições de responsabilidade e comando, dentro e fora da Prefeitura. Insere-se, simultaneamente, em todos os níveis nos quais as decisões são tomadas, tanto pela administração municipal como pela sociedade em sua totalidade. $\mathrm{O}$ autor considera que é preciso decidir planejadamente, tendo em vista uma visão e metas de longo prazo.

Estas decisões requerem, portanto, o atendimento de seis aspectos fundamentais, referentes necessidade de decidir: i) racionalmente; ii) com a mente voltada para o futuro; iii) buscando sempre economizar os escassos recursos disponíveis; iv) focalizando os agentes, ou seja, todos os promotores de ações e, também, as pessoas a serem afetadas por elas; v) focalizando sempre o modo pelo qual todas as ações serão realizadas; vi) buscando estabelecer, na prática, todas as formas possíveis de coordenação dos recursos disponíveis em uma determinada administração (institucionais, humanos, financeiros e outros). Estes pré-requisitos, aliados aos cenários para prever situações futuras, podem garantir a qualidade de vida e a qualidade ambiental dos municípios.

\subsection{As políticas e seus instrumentos de gestão}

A Constituição de 1988 definiu os setores que deveriam elaborar políticas, no interior das quais, seus mecanismos jurídicos, financeiros e técnicos. A política urbana esta entre elas. Em 1998, portanto, já se estabelecia a obrigatoriedade do plano diretor para municípios com mais de 20 mil habitantes (e que continua na atualidade), porém, quando foi aprovado o Estatuto da Cidade (2001) instituiu-se o modelo atual, que inclui requisitos para a proteção às populações vulneráveis e ao meio ambiente. 
Os dados do IBGE permitirão analisar se os governos observam estes vetores principais na elaboração de suas políticas e quais são os instrumentos de gestão territorial que esses municípios dispõem.

\subsubsection{O plano diretor}

A lei determinou aos municípios a indispensabilidade do plano diretor e determinou um prazo para sua elaboração. Para que o sistema de planejamento pudesse funcionar hierarquicamente, deveria iniciar com as diretrizes e estratégias da política urbana mais geral para após elaborar seu plano diretor e detalhá-lo em programas e projetos. Segundo respostas ao Perfil dos Municípios do IBGE (2013) ainda há municípios sem plano diretor, sem se referenciar à existência de uma política específica. Aqueles que já os possuem avançam na execução de suas etapas, muitas vezes com dificuldades operacionais. Dificuldades estas devidas à falta de recursos financeiros, mas também à falta de pessoal qualificado, para citar as duas falhas mais importantes. Do mapeamento desta variável (figura 7) e sua distribuição territorial identificase a sua concentração no centro-sul e dispersa em todas as regiões. Dentre os Estados amazônicos, à exceção do Estado do Para, onde ha mais municipios com planos diretores realizados, os outros ainda não cumpriram sua obrigação. Manaus aprovou seu novo plano diretor em 2013, Belém aprovou-o em 2008 e promoveu sua revisão em 2014; Cuiabá, 2007 tendo sido revisado em 2015.

Considerando o plano diretor como instrumento de planejamento e poder é fundamental sua importância e suas funções definidas para se estabelecer os bons passos para o desenvolvimento municipal. Assim, autoridades e comunidades municipais e principalmente as cidades, podem orientar as bases econômicas do seu desenvolvimento. O Estatuto da Cidade (2001) aponta prioridades para a inserção da questão ambiental e da sustentabilidade urbana, incentivando a cidade compacta e a implantação de centros sustentáveis, acompanhando as diretrizes mundiais do sistema onusiano. 
Figura 7 - plano diretor em municípios com mais de 20 mil habitantes

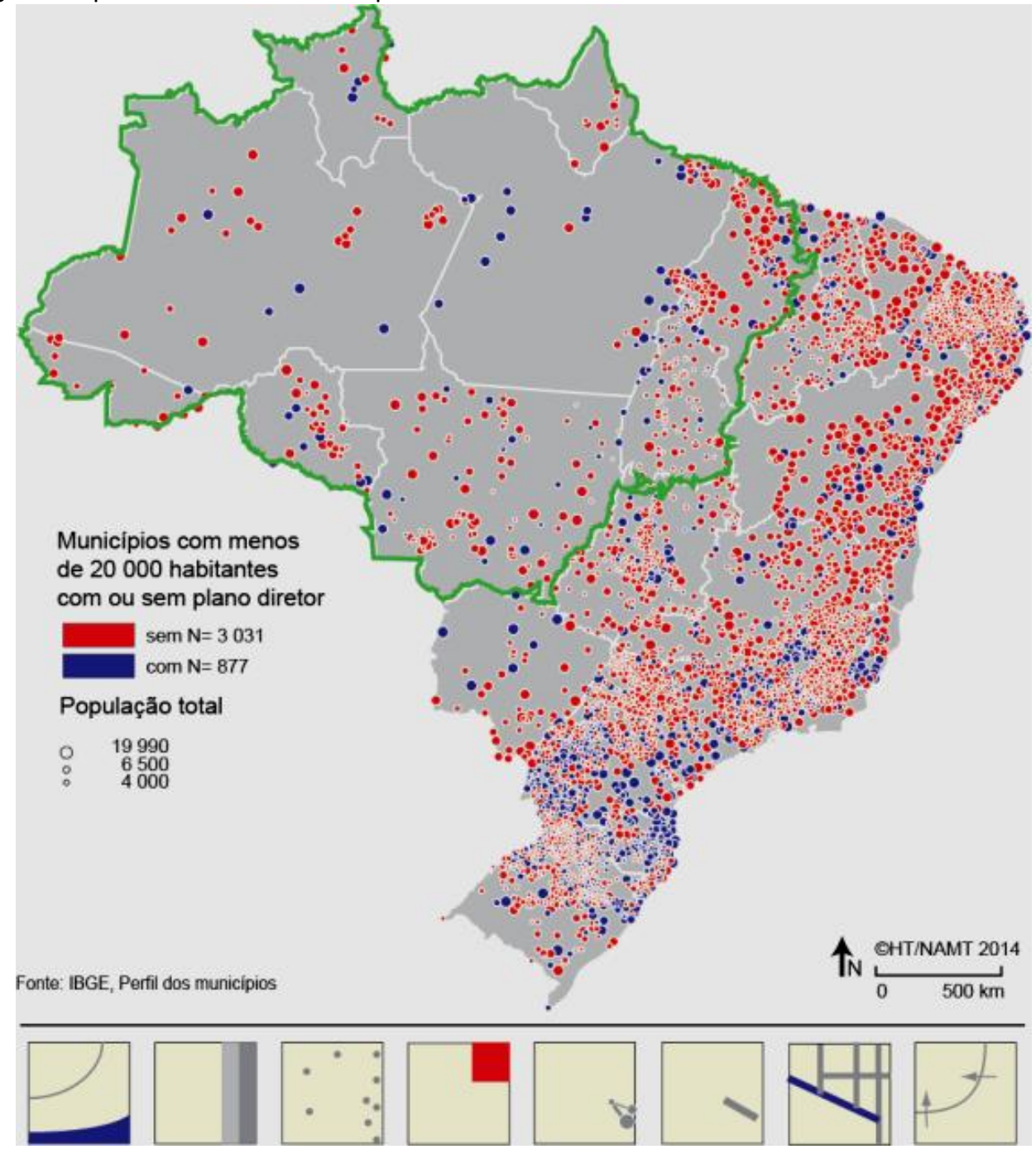

\subsubsection{Despesas municipais em habitação e urbanismo}

Em mais um aspecto, a Amazônia destaca-se pela ocorrência concentrada em suas capitais: as variáveis "despesas municipais em gastos com pessoal nas despesas municipais" e "percentual dos gastos com habitação e urbanismo" foram selecionadas em razão de permitir uma análise mais global da situação nos mais de 5 mil municípios existentes, tanto do ponto de vista do percentual destes gastos quanto em $\mathrm{mi}$ Ihões de Reais. A análise da primeira variável, mapeada na figura 8 , mostra especialmente municípios onde o comprometimento financeiro com o pagamento de pessoal é superior a $92 \%$ - as grandes metrópoles e capitais estaduais. Uma percentagem mais reduzida, porém ainda muito significativa (84\%) é identificada de maneira concentrada em cidades do Nordeste, Norte e Sudeste. Numericamente há muito mais cidades que atingiram $78 \%$ de gastos com pessoal nas despesas municipais. Sozinha esta variável já expressa um endividamento do governo municipal e a impossibilidade de investimento no próprio desenvolvimento local. Por isso, quando se espacializam 
os gastos com habitação e urbanismo os valores são muito menores e os percentuais somente as metrópoles e capitais estaduais tiveram, globalmente, condições de investir entre 21 e $33 \%$.
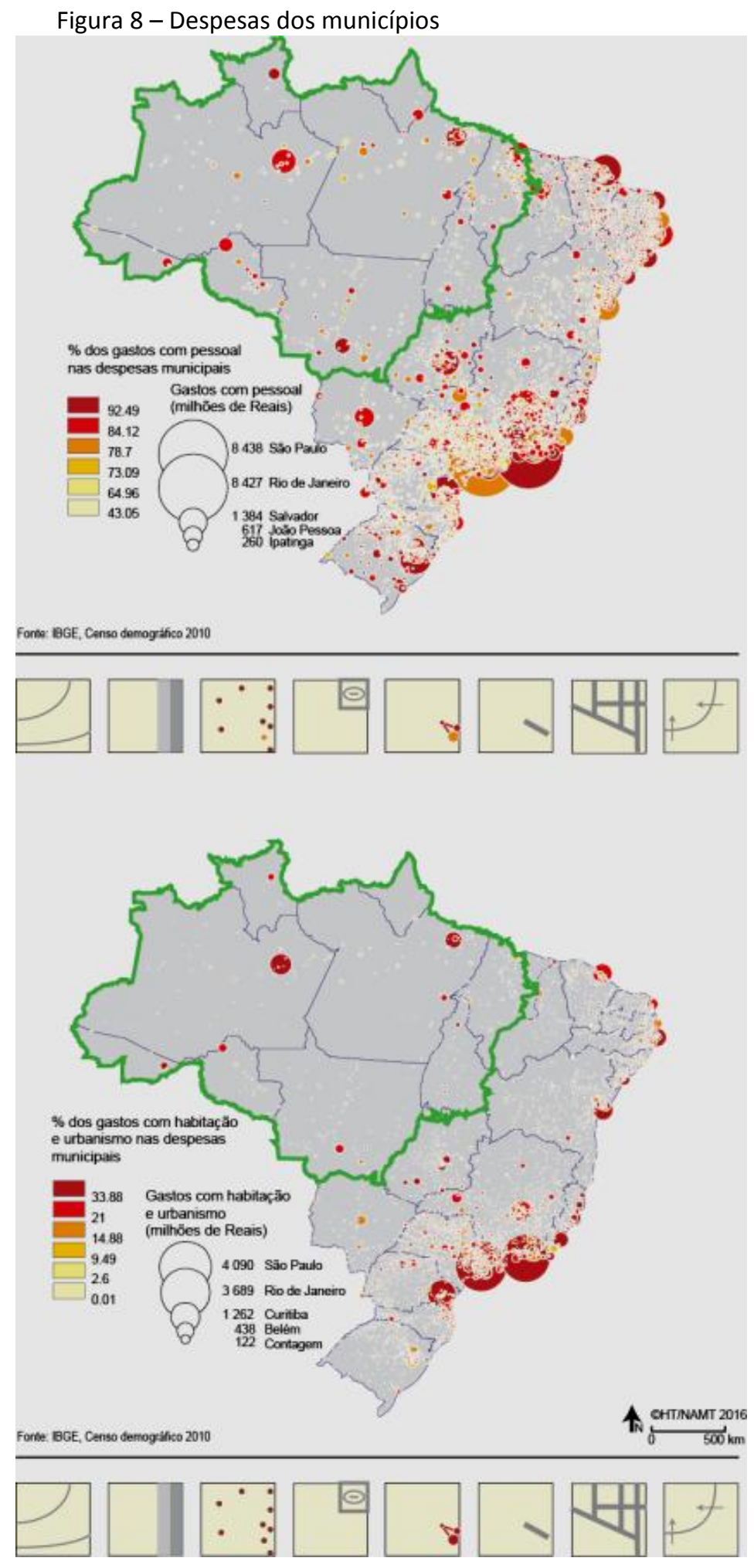

PRACS: Revista Eletrônica de Humanidades do Curso de Ciências Sociais da UNIFAP 


\subsubsection{A condição de funcionários municipais}

A implantação do plano diretor deve seguir uma sequencia lógica de ações, buscando atingir os objetivos e metas que foram definidas e sua execução deve ser acompanhada pelos gestores municipais nos diversos níveis de atuação. Ainda segundo Schweizer (2008) as ações devem ser executadas por servidores municipais dentro de parâmetros pré-definidos de recursos financeiros, materiais, resultados, especificação de qualidade, e num determinado período de tempo. Os componentes de um processo de gerenciamento envolvem desde os recursos financeiros, de tempo, de informações, de licitações, de riscos, à qualidade de pessoas, e, devem visar o bom desempenho e o aperfeiçoamento dos envolvidos.

Assim é indispensável que a municipalidade possua recursos humanos qualificados (em geral e com capacidades específicas). Esta é uma necessidade permanente, pois estes funcionários devem ser capacitados continuamente. $O$ processo de educação e de formação humana e profissional passou a ser permanente pois a velocidade das mudanças tecnológicas pode afetar profundamente a realidade municipal.

A política liberal de redução do tamanho do Estado e do enxugamento de suas instituições certamente promoveu consequências sobre a ação dos governos municipais.

Neste sentido, a figura 9 que nos mostra o total de funcionários ativos da administração direta. Nos chama a atenção a concentração do percentual de funcionários por 10 mil habitantes especialmente nas microrregiões do Nordeste e dos Estados de Goiás e Tocantins no Centro-Oeste. Seria fundamental analisar a eficiência e eficácia dos mesmos no atendimento público e na execução das ações públicas previstas no plano diretor municipal.

A segunda variável mostra o percentual de funcionários estatutários no total de funcionários ativos das municipalidades. Também pode ser preocupante verificar que numerosos municípios aparecem sem a presença de estatutários. Se não ha funcionários, quem cumpre a função de execução dos planos? Normalmente são estagiários, que, por sua própria condição de aprendiz, trabalham por curtos períodos de tempo em uma administração, o que pode ser altamente prejudicial à continuidade de processos de planejamento e execução de políticas públicas. 
Figura 9 - Condições dos funcionários municipais

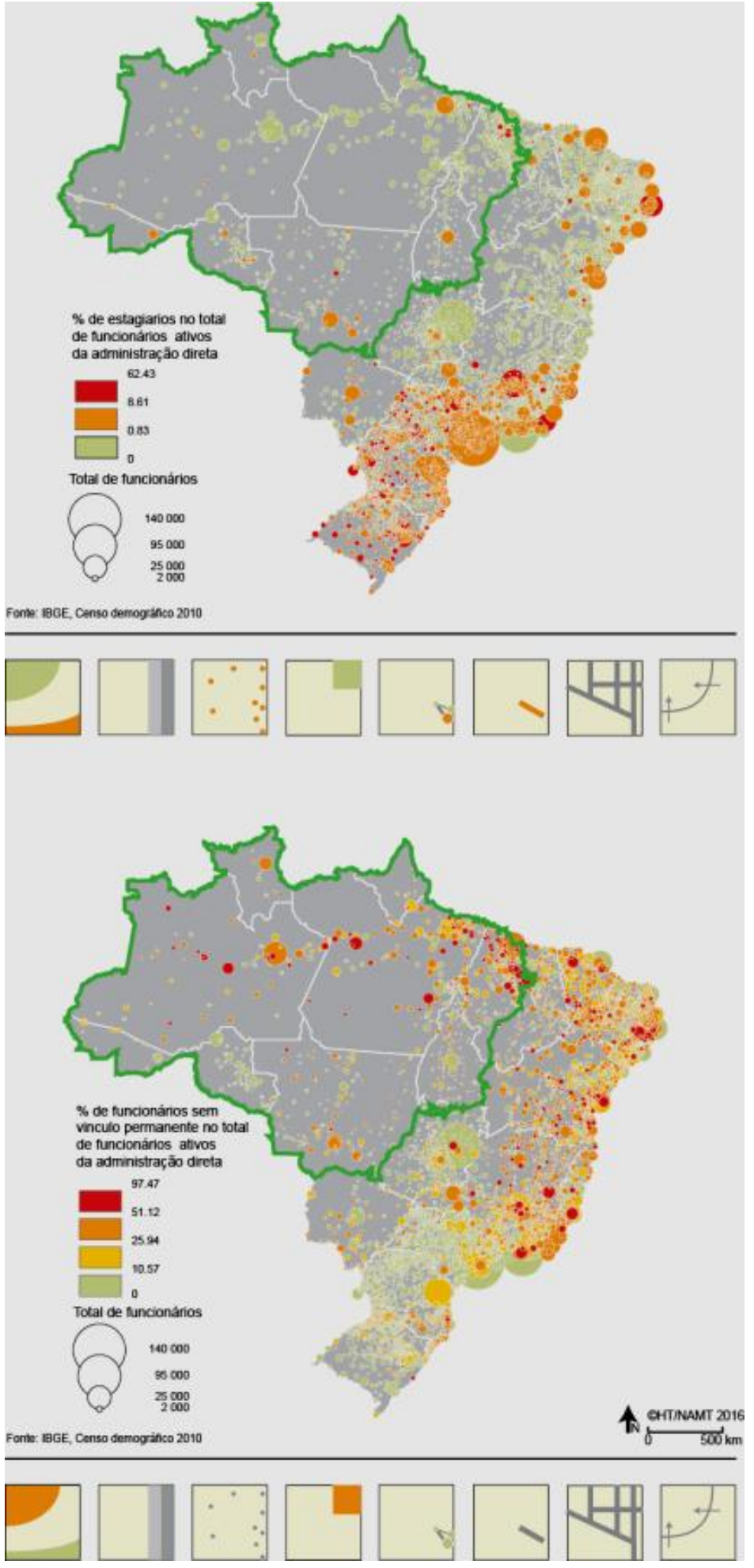

\section{CONCLUINDO}

Sendo assim, pode-se afirmar, pela análise destas variáveis, que apesar das profundas mudanças nos cenários urbanos, da crescente urbanização da sociedade e do

PRACS: Revista Eletrônica de Humanidades do Curso de Ciências Sociais da UNIFAP 
aparecimento dos processos de metropolização, não é uma constante no país a prática do planejamento como uma cultura de antecipação de ações que fundamentam o desenvolvimento e a qualidade da vida urbana.

Não por falta de dados e de informações: do ponto de vista de uma fundamentação que dê suporte técnico às decisões, atualmente, as instituições de pesquisa estatística os disponibilizam a quem quer que seja. Mas os orçamentos das municipalidades estão comprometidos com gastos de pessoal e praticamente inexistem recursos para investimentos. Outro elemento destacado por meio das variáveis analisadas é o baixo atendimento às exigências de elaboração de um plano diretor induzindo ao questionamento do número elevado de funcionários e uma baixa proporção de municípios que cumpriram esta exigência. Por que os planos diretores ainda não foram elaborados? Se não foram concluídos, como a sustentabilidade urbana pode ser alcançada? Numerosas experiências aparecem nos cenários nacional e locais, propostas de conscientizar, entre elas, visando reduzir os conflitos de interesses entre os atores públicos, privados e população. Porém, como são parciais, não criam condições de mudança significativa para o desenvolvimento local.

Entendendo que muitas das condições institucionais foram criadas para que as políticas e as ações públicas pudessem ser realizadas, podemos concluir também que apesar das tendências e da existência de mecanismos para o planejamento, sua execução ainda esta longe de mudar as velhas práticas. Os cenários são novos, mas as práticas permanecem velhas... E, as cidades amazônicas reproduzem o mesmo padrão.

Os gestores públicos ou não conseguem articular e integrar os complexos processos urbanos ou não tem interesse em, realmente, buscar soluções que visem mudar a fragmentação, a desigualdade e as disparidades. Setores urbanos mais dinâmicos vêm sendo estrategicamente oferecidos à construção de uma imagem de cidade competitiva, mundial, e que pode oferecer à venda que tem de melhor. Setores periféricos, menos dinâmicos ou que não possuem elementos atrativos são deixados ao seu próprio destino, mesmo que sejam locais onde possam surgir empreendimentos fora da economia formal, criativos.

Não se pode reproduzir, em pleno século XXI, o que Jane Jacobs (Vida e morte das grandes cidades americanas) já analisava em 1961, em sua primeira edição, sobre as ruas seguras e inseguras, sua função dentro do complexo urbano, sobre o perigo de acabar com as diversidades. Mudanças radicais e a efervescência do final do século XIX que Karl Schorske analisa em Viena fin-de-sciècle (1961) que, resultara nos movimentos de rompimento com a aristocracia e seu modo de vida, conseguiu ver um fio unificador das transformações em diversas áreas culturais e no urbanismo. Mas, talvez possamos ter um novo olhar, valorizando a criatividade nas cidades (Fonseca Reis e Kageyama, 2011) como forma de romper com o modelo atual. 


\section{REFERENCIAS}

BRANDÃO, Carlos Antonio. Teorias, estratégias e políticas regionais e urbanas recentes: anotações para uma agenda do desenvolvimento territorializado. Revista Paranaense de Desenvolvimento. Curitiba, n. 107, p. 57-76, jul/dez. 2004.

FONSECA, Fernando P.; RAMOS, Rui A. R. O Planejamento Estratégico na busca de potenciar o território. IN XI Jornadas da Associação dos Urbanistas Portugueses Territórios e Desenvolvimento - Os argumentos e a disciplina do urbanismo. 2004. Disponível em: <https://repositorium.sdum.uminho.pt/bitstream/1822/1348/1/XI Com6a.pdf >. Acesso em 02 ago. 2010.

FONSECA REIS, Ana Carla e KAGEYAMA, Peter. Cidades criativas: perspectivas. São Paulo: Garimpo de Soluções, 2011.

INSTITUTO DE PESQUISA ECONOMICA APLICADA. Gestão do uso do solo e disfunções do crescimento urbano: instrumentos de planejamento e gestão urbana em aglomerações urbanas: uma análise comparativa. Brasília, IPEA, 212 p. 2001.

INSTITUTO BRASILEIRO DE GEOGRAFIA E ESTATÍSTICA. Divisão territorial brasileira (DTB). 2014. Disponível em: <http://downloads.ibge.gov.br/downloads_geocienci as.htm>. Acesso em 08 set 2015.

INSTITUTO BRASILEIRO DE GEOGRAFIA E ESTATÍSTICA. Perfil do Municípios Brasileiros. Rio de Janeiro, IBGE, 120 p. 2013. Disponível em: http://loja.ibge.gov.br/perfildos-municipios-brasileiros-2013.html. Acesso em 08 set 2015.

INSTITUTO BRASILEIRO DE GEOGRAFIA E ESTATÍSTICA. Regic, 2007. Disponível em: http://downloads.ibge.gov.br/downloads_geociencias.htm. Acesso em 02 ago.2010. INSTITUTO BRASILEIRO DE GEOGRAFIA E ESTATÍ́STICA. Regiões de Influência das Cidades/Regic 1993, Rio de Janeiro, IBGE, Departamento de Geografia, 230p, 2000.

MMA/PNUD - Parceria 21: IBAM/ISER Formulação e implementação de políticas públicas compatíveis com os princípios de desenvolvimento sustentável definidos na Agenda 21 - Cidades Sustentáveis da Agenda 21 Brasileira, mimeo, 1999.

SCHWEIZER, P. Tirando o Plano Diretor da Gaveta, Revista de Administração Municipal, n. 265, p.55-68, 2008.

SMITH, Neil. Geografia da diferença e as políticas de escala. In: ARANTES, Antonio A. 0 espaço da diferença (org.). Campinas: Papirus, 2000.

THÉRY, H.; MELLO-THÉRY, N. Ap. Atlas do Brasil: disparidades e dinâmicas do território. São Paulo, Editora da Universidade de São Paulo, 3a edição (no prelo), 2016.

Artigo recebido em 14 de julho de 2016.

Aprovado em 18 de julho de 2016. 